\title{
Editorial
}

\section{Barbara Lothenbach}

Laboratory for Concrete and Construction Chemistry, Head

Thermodynamic Modelling Group, EMPA, Switzerland

Concrete, based mainly on Portland cement, is the most widely used building material. The manufacturing of Portland cement causes $5 \%$ of the carbon dioxide emissions worldwide, even though per tonne of concrete much less $\mathrm{CO}_{2}$ is set free than, for example, by the production of the same amount of steel or aluminium. The problem lies in the quantity, every year three billion tons of cement is produced throughout the world and the trend continues upwards. One way of reducing $\mathrm{CO}_{2}$ emissions related to cement production is by using alternative raw materials with lower carbon content or industrial by-products and, in addition, ensuring that structures built last longer. To optimise a better understanding of cement and concrete, research on all aspects of cementitious materials is mandatory. The topical content of this issue of Advances in Cement Research reflects the broadness of various aspects of cement-based materials.

Mineralisers can be used to lower clinkering temperature and thus to reduce energy consumption. The contribution of Agarwal et al. (2015) demonstrates that the use of jarosite, a by-product of the zinc industry, as a mineraliser allows a lowering of the temperature needed for clinkering and how, at a constant temperature, the use of jarosite results in enhanced alite formation and increased compressive strength of mortar samples.

The blending with alternative materials lowers the clinker factor in the cement. Generally, limestone, fly ash or blast furnace slags are used. However, the use of glass powder can also contribute to the compressive strength of cement pastes, refine porosity and decrease expansion related to alkali silica reaction of mortars, as demonstrated in the paper by Liu et al. (2015).

There is an increasing interest in the development and characterisation of alternatives to Portland cement as a binder in concrete. Alternative binders such as calcium aluminate and calcium sulfoaluminate cements, alkali-activated or supersulfated cements have been studied extensively. The paper by Murmu and Singh (2015) reports on the strength and hydration products of ground granulated blast-furnace slag activated with lime and calcium sulfate.

Calcium silicate hydrates (CSH) are the main phase in hydrated cements and strongly influence the mechanical properties of cementitious materials. The structural, dynamic and mechanical properties of CSH are addressed by molecular dynamics in this issue of Advances in Cement Research in the paper by Hou and Li (2015).

Microbial-induced calcium carbonate formation as a method for the protection of cement-based materials is the topic of the contribution of Senthilkumar et al. (2015). The formation of calcium carbonate by microorganisms from different calcium sources (calcium hydroxide, calcium acetate, calcium chloride and calcium oxide) is investigated. The surface treatment by microorganisms showed promising prospects for increasing strength and durability.

The use of superplasticisers plays an important role in the production of denser and thus more durable mortars and concretes. The paper by Anagnostopoulos (2015) presents a laboratory study of the effects of a polycarboxylate superplasticiser on the rheological and mechanical properties.

\section{REFERENCES}

Agarwal SK, Ali MM, Pahuja A, Singh BK and Duggal S (2015) Mineralising effect of jarosite: a zinc industry by-product in the manufacturing of cement. Advances in Cement Research 27(5): 248-258, http://dx.doi.org/10.1680/adcr.13.00102.

Anagnostopoulos CA (2015) Effect of superplasticiser type on the properties of cement grouts. Advances in Cement Research 27(5): 297-307, http://dx.doi.org/10.1680/ adcr.14.00001.

Hou D and Li Z (2015) Large-scale simulation of calcium silicate hydrate by molecular dynamics. Advances in Cement Research 27(5): 278-288, http://dx.doi.org/10.1680/ adcr.13.00096.

Liu S, Xie G and Wang S (2015) Effect of glass powder on microstructure of cement pastes. Advances in Cement Research 27(5): 259-267, http://dx.doi.org/10.1680/ adcr.13.00100.

Murmu M and Singh SP (2015) Strength characteristics of limeactivated slag cement. Advances in Cement Research 27(5): 268-277, http://dx.doi.org/10.1680/adcr.13.00097.

Senthilkumar V, Palanisamy T and Vijayakumar VN (2015) Strength characteristics of microbial cement mortars treated in different calcium sources. Advances in Cement Research 27(5): 289-296, http://dx.doi.org/10.1680/adcr.14.00002. 